\title{
World class university publication pressure across different systems
}

Post, David

Pennsylvania State University, United States (dmp10@psu.edu)

Chou, Chuing Prudence $\bowtie$

National ChengChi University, Taiwan (iaezcpc@nccu.edu.tw)

Ishikawa, Mayumi

Osaka University, Japan (ishikawa@cgin.osaka-u.ac.jp)

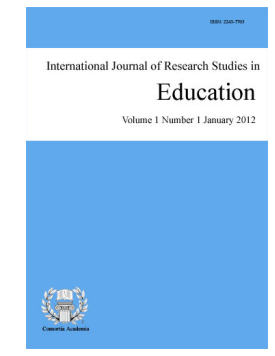

ISSN: 2243-7703 Online ISSN: 2243-7711

OPEN ACCESS

\section{Li, Jun}

Western University, Canada (jun.li@uwo.ca)

Soudien, Crain

University of Cape Town, South Africa (csoudien@hsrc.ac.za)

Welch, Anthony

The University of Sydney, Australia (anthony.welch@sydney.edu.au)

\section{Abstract}

This synthesis of a multi-year cross-national collaboration first reviews the changes facing educational researchers due to pressures to create "world class" universities. The paper then reports key findings from a comparative case study of publication patterns in South Africa, Australia, Mainland China, Hong Kong, Taiwan, Japan, and the United States (US) during the three-time slots of 1993, 2003, and 2013. The authors adopted a common research design, by selecting two departments at one public university from each system. It was found that except for the US, most faculty members in other systems were forced to change not only their publication into English but also their research topics in order to capture the interest of an international readership. In cases where English is not the predominant language of use, these trends negatively impacted scholarship in the predominant local language(s) of use. The paper concludes that the costs of using comparable measures of quality to compare "world class" universities are not borne equally across, or within, higher education systems.

Keywords: comparative education, higher education system, publications, SSCI, world-class universities 


\section{World class university publication pressure across different systems}

\section{Introduction}

How do educational researchers and the institutions measure the quality of their work and its worth? And how do the answers to these questions differ around the globe? If a world trade in services and ideas promotes competition for market shares of both goods, then its reasonable that the producers of these goods should compete with each other for top rank in perceptions of quality and value. But what can serve as a universal metric, a convertible "currency," so that the consumers and investors (students and industry) can shop across borders?

Today's most common currency in higher education institutes (HEIs) seems to be measured as faculty publication output and citation by other researchers than any actual essence of learning or direct assessments of research importance in the race to create "world class" universities (Post \& Chou, 2016). Here, we discuss the varied reasons for the emergence of publication indexes as measures of productivity, summarizing the preliminary findings of an on-going, cross-national collaborative project about the globalization of education research. First, we report our study of faculty adaptation in Australia, South Africa, Mainland China, Hong Kong, Taiwan, and Japan. Then we discuss why faculty in the US are less affected from the study.

Our findings problematize both facile comparisons as well as the notion that English-language citable research is a useful end goal. The common metrics of quality and productivity may facilitate the mobility of faculty members, but there are costs are high and of mixed results in many HEIs across the globe.

\section{Institutional and historical context}

Over the past three decades, numerous publications and initiatives throughout the globe released annual reports ranking universities based on a variety of metrics. One such initiative, $U$-Multi-rank, has a multi-level methodology which embraces 500 universities from more than sixty countries, including 25 percent from non-EU nations (Hazelkorn, 2013).

For increasingly hard-pressed academic staff, such accountability often feels more like an exercise in accountancy (Welch, 2005), as publication numbers are relentlessly tallied, amid rising overall demands for enhanced institutional ranking and reputation. Audit culture, in effect a modified, latter-day form of Taylorism, differs somewhat from place-to-place; nonetheless is increasingly being seen as relevant to the lifeworld of contemporary higher education worldwide (Welch, 1998, Shore, 2008, p. 279). Effectively it describes a system that subjects individual performance to audit by external 'experts'; work performance, in core areas such as teaching and research, is routinely measured against external benchmarks.

Part of the political technology of audits was the emergence of a category of 'experts', including in higher education, who deployed their specializations to develop classification systems, institutional procedures for their implementation, new regulatory systems, also made their expertise available to individuals subjected to such audit processes. "The new experts, referred to as 'educational development consultants', 'quality assurance officers', 'staff development trainers' and 'teaching quality assessors', are fulfilling these four functions" (Shore \& Wright, 1999, p. 560).

The introduction of such measures, at national and institutional levels, has meant that in many countries ranking has become an industry, and those who work within institutions have largely been transformed into 'responsible and calculating' self-managing subjects who no longer much question the proliferation of such technologies of control as audit schemes, but rather become complicit in their maintenance (Miller, 2001, p. 380, Shore \& Wright, 2015, Hazelkorn, 2011).

72 Consortia Academia Publishing (A partner of Network of Professional Researchers and Educators) 


\section{Theory and Methods}

Globalization and the entrenchment of neo-liberal ideology have had a profound impact on higher education policy and governance (Chou \& Ching, 2012). Many higher education institutions (HEIs) are geared toward pursuing internationalization to strengthen their global competitiveness and the achievement of world-class status, with the hope of increasing their international visibility and educational markets (Lo, 2014; Mok, 2014). These influences on higher education have fostered an ideology of 'new managerialism' among manager-academics within HEIs as manager-academics have embraced its principles of maintaining relationships of power and domination (Deem \& Brehony, 2005). Whereas higher education was not traditionally associated with the dominance of management, concerns over quality audit and assessment of research and teaching in higher education legitimate the right of university managers, often those in senior positions or permanent managerial posts, to manage.

Burton Clark's (1986) 'triangle of coordination' model explained the relationship of factors that influence the performance of higher education systems. The three legs of the triangle were the state, 'academe' meaning colleges and universities collectively, and the market. Clark's model is not intended to be viewed as a blueprint, but the model illustrates how as the factors changed and influenced one another the shape of the triangle would change; however, it would always remain a triangle. In this study, we attempt to apply Clark's 'triangle of coordination' to the effects of globalization, neoliberalism, and 'new managerialism' in higher education (Figure 1). While the foundations of Clark's model apply to the study, we argue that the previously mentioned phenomena must be included in the triangle as sub-factors.

First, our project attempted to quantify the publications by all research faculty members affiliated in each of the 12 research universities in Australia, China, Hong Kong, Japan, Taiwan, South Africa and the United States. In each university, the information collected was from staff employed in the Departments of Education, and Anthropology. In the case of Taiwan, information collected was from a Department of Ethnology as the university utilized for data collection does not have a Department of Anthropology. In the case of South Africa, this research utilized in-depth interviews of select scholars from the Department of Education and Anthropology at a top university in the country. This is due to data collection issues encountered in South Africa. By collecting Curricula Vitae and using electronic data bases such as Google scholar, InCite, SCOPUS and JSTOR, we connected the names of past department members with the titles and (where possible) abstracts or keywords of all academic publications in serial periodicals in 1993, 2003, and 2013.

Second, we tabulated the articles according to their language, e.g. English, Chinese, Japanese, as well as the numbers of these articles which were published in the three timelines according to the location of the journal's publication. Third, we calculated the numbers of articles appearing in journals that were produced in the country where the researcher worked. In addition, we further tabulated the number of articles in each year that appeared in journals produced outside of the country, considered as "international" publications. Our project focused on the relationship between researchers and their publications instead of the publication status itself. Fourth, we attempted to gather abstracts and key words from the articles published in 1993, 2003, and 2013, and then coded all articles as focused on a national or on a non-national theme. Finally, to help us interpret the trends of the quantitative data on publication, we identified and interviewed two junior and two senior academics of each department in each case, respectively having below three years, and minimum twenty years, of experience at the university.

\section{Key Findings of the Comparative Case Study}

\subsection{Audit Culture and Academic Production in Australia}

At the focal Australian university, our tabulations show that articles published 1993-2013 continued to be overwhelmingly written in English (Table 1). When challenged some years ago, at a high-level university board 
Post, D., Chou, C. P., Ishikawa, M., Li, J., Soudien, C., \& Welch, A.

meeting regarding why the university should not give equal weight to publications in other languages, the Vice Chancellor acknowledged as a good idea, but 'in theory'. In practice, however, nothing changed over the 20-year period. Unsurprisingly -no social science publications were in non-English language submitted by Australian universities for review, as part of ERA 2012. Interviewees provided further evidence of the discounting of publications in other languages, an interviewee in an education department explained:

"I've been delighted to publish work in other languages, and help with translations where that was possible. And I used to be (angry) with the auditors because they made it so difficult to have such work counted. After a while I decided that arguing with them was an utter waste of energy. If the University, and the national system, didn't actually practice what they preached - in terms of valuing global outreach and reputation - then so much the worse for them."

Table 1

Australia Case: Journal Language (1993-2013)

\begin{tabular}{lcccc}
\hline \multicolumn{1}{c}{ Department } & Year & Staff Numbers & $\begin{array}{c}\text { Number of Articles } \\
\text { Published }\end{array}$ & $\begin{array}{c}\text { Percentage (\%) in } \\
\text { English }\end{array}$ \\
\hline Anthropology & 1993 & $5 / 5$ & 14 & 100 \\
Anthropology & 2003 & $8 / 8$ & N/A & 100 \\
Anthropology & 2013 & $17 / 20$ & 15 & 85 \\
Education & 1993 & $52 / 52$ & 123 & 100 \\
Education & 2003 & $47 / 48$ & 90 & 98 \\
Education & 2013 & $54 / 57$ & 87 & 95 \\
\hline
\end{tabular}

What changed over 1993-2013 was not language but in-fact, in both Anthropology and Education, there were far more publications in non-Australian journals (Table 2). In Anthropology, the increase was 50 percent while 350 percent in Education. The effects of ranking journals, evident in the trend towards publishing more in 'International' journals, is particularly influential on scholars of Australian education, or local indigenous cultures, for example, who may well find it more difficult to place their work in listed international journals. Do such local specialists run the risk of publishing locally, perishing globally (Hanafi, 2011)?

Table 2

Australia Case: Journal Origin (1993-2013)

\begin{tabular}{lcccc}
\hline \multicolumn{1}{c}{ Department } & Year & Staff Numbers & $\begin{array}{c}\text { Number of Articles } \\
\text { Published }\end{array}$ & $\begin{array}{c}\text { Percentage }(\%) \\
\text { International }\end{array}$ \\
\hline Anthropology & 1993 & $1 / 5$ & 14 & 20 \\
Anthropology & 2003 & $4 / 8$ & N/A & 20 \\
Anthropology & 2013 & $6 / 20$ & 15 & 30 \\
Education & 1993 & $10.3 / 52$ & 123 & 19.8 \\
Education & 2003 & $23.9 / 48$ & 90 & 49.6 \\
Education & 2013 & $39.5 / 57$ & 87 & 69.3 \\
\hline
\end{tabular}

The reason is the perceptible rise of the audit culture resulted in strong signalling to researchers concerning which journals were preferred. Indeed, in 2010 journals were specifically accorded either an $\mathrm{A}^{*}, \mathrm{~A}, \mathrm{~B}$ or $\mathrm{C}$ rank in the national evaluation process, a process in which few Australian journals were accorded an $\mathrm{A}^{*}$ or A rating. The research field 'Education' contained only 2 Australian journals (3 Australian journals for Anthropology). In later years, the former ranking was replaced with a more refined indicator that included a profile of journals and conferences for each discipline, ordered by descending frequency of publication. However, this had little impact on scholarly decisions about where to publish during the period we reviewed. Moreover, the effects of ranking were hammered home at the institutional level by regular messaging from the administration as academics were schooled regarding which journals, they should choose and which were less well regarded. As a young researcher in education confessed, "(I) am aware of a tacit understanding that in order to progress in my career, even get or keep the job, my publications must 'count'.... Even if it may contribute to some greater social cause or principle relating to sharing knowledge more widely in which I believe, I would unfortunately have to, in

74 Consortia Academia Publishing (A partner of Network of Professional Researchers and Educators) 
some ways, perceive (publishing in non-SSCI journals) as a luxury that, in my current personal and professional situations, I cannot afford".

The perception of surveillance and audit clearly influences decisions about where to publish which also has a great impact on older academics.

\subsection{South African Pressures and Push-back}

Our South African case study was in an institution that would have been classified as white in the apartheid era. The research that informs this study is drawn from in-depth interviews of four senior academics from the aforementioned institution. This is due to complications regarding data collection in the country. Two of these academics work in the field of social anthropology and the remaining two scholars work in the field of education, sociology of knowledge and education policy. The subjects were selected because of the time they had spent in the institution, alongside the roles they play and continue to play in the Humanities faculty of the institution studied.

In recent years, the incentive and reward system for publishing in the country has been based on a subsidy model managed by the Department of Higher Education and Training (DoHET). DoHET allocates research subsidies based on publication in one of about 3000 approved journals. Institutions receive the equivalent of US\$12,000 for every article published in one of these journals and R1m (approximately US\$80,000) for an accepted monograph dependent on its number of pages. The government also established a grant-making structure, the National Research Foundation (NRF) aims to support the growth of research in a number of strategically chosen thematic fields. An additional incentive mechanism in the national system of innovation is the rating of researchers. One intention of this, is to encourage researchers to publish in particular journals.

These policies have received push-back (Jansen, 2013, p. 15) that responding to the global pressure to publish in high-impact factor journals would discourage academics from addressing local issues.

(W)hat is more important? That you produce lots of research in science journals that is cited by your peers in Norway and Boston? Or that the knowledge you produced through research in your school of engineering solved problems of annual flooding in the squatter housing of Khayelitsha and Kwa Mashu? Or that the applied research produced through your school of education actually made an impact on turning around disadvantaged schools in Orange Farm or Zwelitsha?

One interviewee in Education took a more positive view, arguing that it was necessary to work with and to take advantage of the international turn. For him it was the exposure and interfacing with the global that drove change, and was less about managerialism. He acknowledged that the emerging performance management criteria led to anxiety and a shift from competence to performance. On the positive side, this led to more academics publishing in high-impact journals. On the negative side, "by the 2000s the trend was towards outputs rather than substance." As an interviewee explained to us, there is a risk of homogenization:

"Trying to be World Class by holding on to the edges of discussions has its price - you can't just quickly frame something in exactly the way that there's a purchase for it ..."

This suggests that while output might have increased in recent years, the overall quality of these research articles might have declined. As another of our informants remarked: "There has been a pressure ... the bars are now much higher and the consequences are that people are much more individualistic in their efforts to do research - each individual is kind of going out to make their own mark." A different education researcher echoed that position, finding that there has been a "weakening of the local discussion and the undergraduate and graduate course content", which must also have consequences for the quality of the research output. The same informant was "[1]ocal publishing has led to discrimination when it comes to promotion regarding research 
score." Those who have followed the university guidelines might have advanced themselves but un, "a shift from interventionist/activist to more formal expectations."

In foregrounding individual advancement, through emphasizing individual outputs and individual citations, are South African educational researchers sacrificing the urgency and relevance of the local?

\title{
4.3 Evaluationism in Mainland Chinese Universities
}

The importance of research in Mainland Chinese universities in general, and in our focal institution, is manifest in regular, institutional assessment of research output by of faculty members. Research assessment exercises in Mainland Chinese universities measure publications in SCI, EI or SSCI journals and create as a core indicator for faculty advancement, substantiation and awards. Education researchers are judged by both their numbers of publications and their number of SCI, EI or SSCI journal articles. These criteria vary across different disciplinary areas and among different ranks of professorship. Quite different from the other systems we investigated, in Mainland China there are strong incentives to publish internationally rather than locally: weighted salary bonuses are given for indexed journal articles in English. These practices were termed as "evaluationism" by academics at the mainland case university.

Evaluationism creates unequal pressures on academics. In our study we found that senior faculty members were better able to publish according to their personal interests and motivations. As an interviewee commented:

\begin{abstract}
"In the earlier times there were no such things as annual appraisal for promotion or research assessment for tenure at my university. That time not everyone published, except for a few very senior colleagues who just published something. What we measured were the academic interest in and commitment to research, instead of research outputs, not mentioning the indicator of quantity."
\end{abstract}

The junior faculty members we interviewed did not experience this same optimism and morale. One interviewee felt direct pressure relating to his research outputs as measured by the research assessment exercises. He mentioned he must work as hard as possible to be more prepared and competitive when the time came for his tenure application one year later.

The emphasis on SCI, EI and SSCI journal articles in English for evaluation was supported by both junior and senior faculty members who tended to view the global ranking regime as one way of the internationalization and standardization of research outputs (Tables 3 and 4 and Figures 2 and 3). However, senior professors were much less affected by evaluation pressure. In terms of topic and language preference for publications, both senior and junior faculty members tended to emphasize local relevance. This local emphasis appears to contravene our focal institution's calls for publications with a global impact. Our junior faculty members did not agree, as expressed by one interviewee:

\begin{abstract}
"In general, my colleagues don't have many publications in English, and there is no significant change. One of the reasons [for this] is that publications in English have fewer readers from our domestic academia, therefore have little impact. For the majority of my colleagues here publications in English are not the first choice. However, there are two to three colleagues who are active in English publications, which is good for the global impact of higher education research from China."
\end{abstract}

\subsection{Taiwan and the SSCI Syndrome}

The Taiwanese government responded to the twin pressures of competitive university rankings and higher education expansion with policies that emphasized quantitative research, and with new probation and self-evaluation system to monitor faculty research output. Subsequently, an "SSCI Syndrome" in higher education emerged, especially in the humanities and social sciences, creating a dilemma for faculty who were

76 Consortia Academia Publishing (A partner of Network of Professional Researchers and Educators) 
World class university publication pressure across different systems

forced to choose between local relevancy and international academic visibility, and deemphasizing teaching (Suh \& Park, 2014).

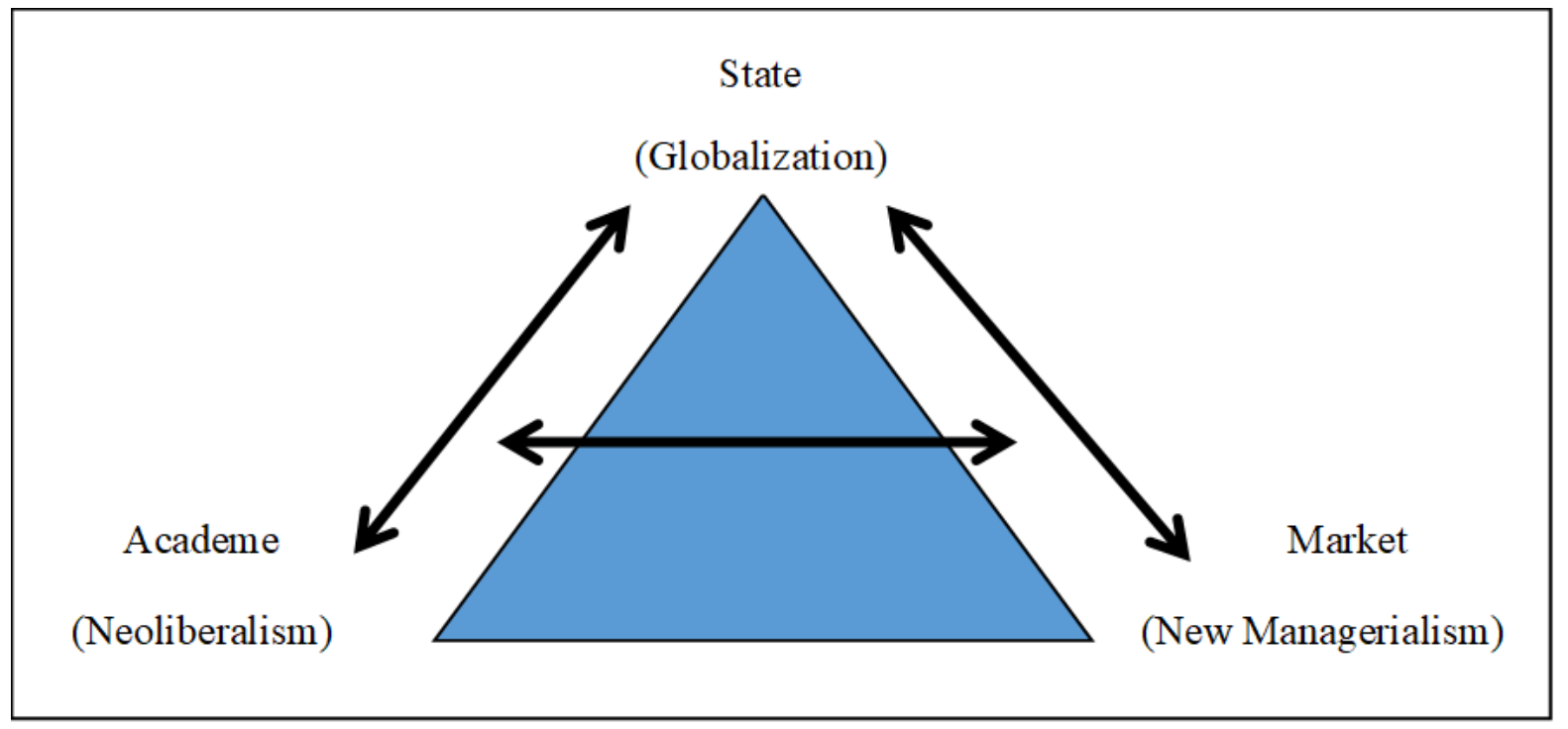

Figure 1. Globalization, neoliberalism, and new managerialism in Burton Clark's 'Triangle of Coordination' Model

Table 3

Mainland China and Hong Kong cases: Statistical trends of journal articles and faculty members (1993-2013)

\begin{tabular}{lcccc}
\hline & 1993 & 2003 & 2013 & Total \\
\hline Top Chinese University (TCU) & $18 / 13$ & $66 / 21$ & $54 / 26$ & $138 / 60$ \\
Top Hong Kong University (THKU) & $9 / 19$ & $55 / 23$ & $42 / 28$ & $106 / 70$ \\
Top Japan University (TJU) & $15 / 10$ & $26 / 9$ & $18 / 8$ & $59 / 27$ \\
Overall & $42 / 42$ & $147 / 53$ & $114 / 62$ & $303 / 157$ \\
\hline
\end{tabular}

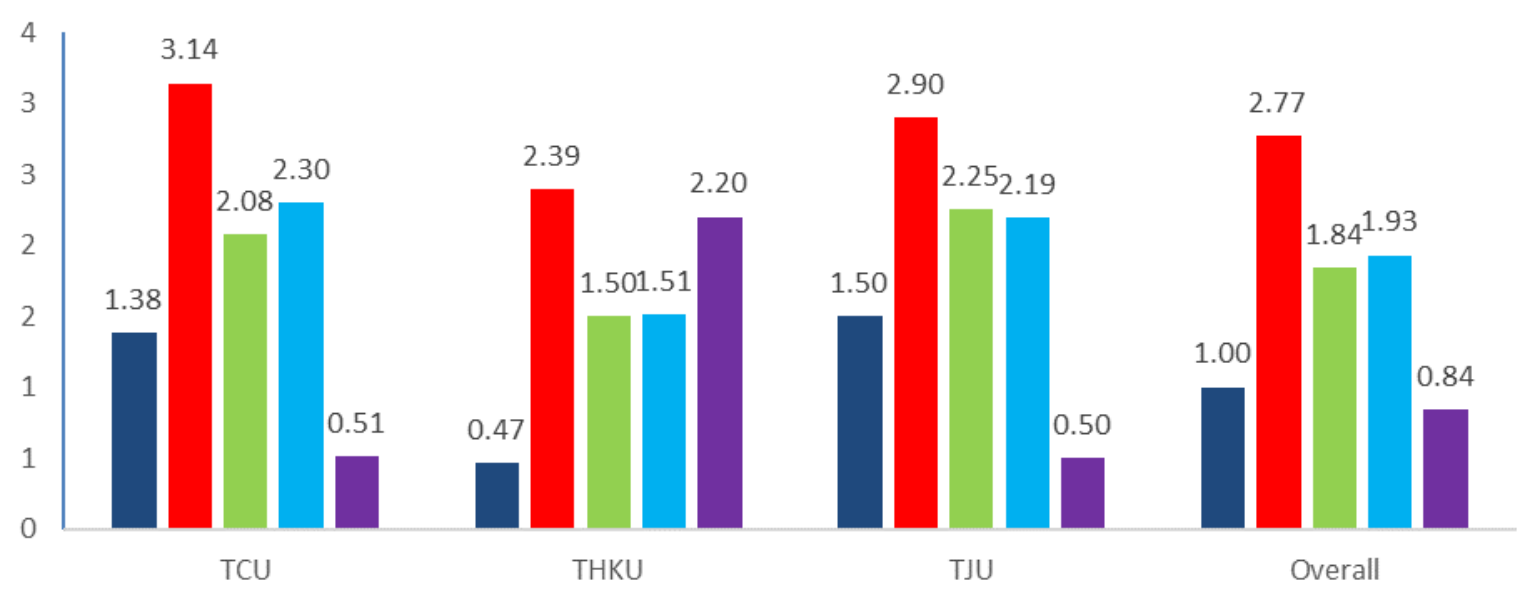

Figure 2. Ratio Trends of Journal Articles and Faculty Members (1993-2013)

Prior to 1994, higher education policy in Taiwan had been supported for reasons of economic development and political stability. The government implemented strict controls over establishment of new institutions, and faculty and student affairs on campus (Mok, 2014). After 1994, the MOE launched a series of policies, with the result that today nearly 70 percent of Taiwan's 18-22 age cohort studies in a postsecondary institution (the second highest rate in the world after South Korea), and, rather like Japan, made weaker institutions more 
vulnerable to failure.

Taiwan first promoted the "World-Class Research University Project" in 2003, and subsequently the Higher Education for Excellence Plan. In the first, fiercest round of competition, twelve Taiwanese HEIs were selected to receive additional funding over a span of five years. The project was renewed in 2011 to further increase universities' cross-border collaboration and publication, and to compete for global talent.

As a result, the so-called "SSCI syndrome" has overwhelmed our target Taiwanese university. Education faculty members are expected to engage in both teaching and research on policy- and school-related affairs. Before 2003, most Education researchers earned promotions based on their book publications, which carried most weight. The academic educational community also did not encourage English-medium research and this was less likely to be accepted for publication. In both 1993 and 2003, we found that all of the Education Department researchers' publications were in Chinese, which was (and is) the medium of instruction. But after 2003 this percentage declined to 74 percent, while the Department's English-medium publications increased. By comparison, we also looked at publications by faculty in Ethnography, who continued to publish in Chinese throughout the period (Table 5).

Table 4

Mainland China and Hong Kong cases: Trends of journal articles in English and native languages (1993-2013)

\begin{tabular}{lcccc}
\hline & 1993 & 2003 & 2013 & Total \\
\hline Top Chinese University (TCU) & $1 / 16$ & $4 / 60$ & $3 / 50$ & $8 / 126$ \\
Top Hong Kong University (THKU) & $5 / 4$ & $26 / 31$ & $34 / 8$ & $64 / 43$ \\
Top Japan University (TJU) & $0 / 15$ & $1 / 25$ & $1 / 17$ & $2 / 57$ \\
Overall & $6 / 35$ & $31 / 116$ & $38 / 75$ & $74 / 226$ \\
\hline
\end{tabular}

Note. Data excluding those that were published in bilingual journals or other local languages.

\section{Table 5}

Taiwan Case: Publication rate and percentage in English 1993-2013

\begin{tabular}{ccccc}
\hline \multirow{2}{*}{ Date Point } & \multicolumn{2}{c}{ Education Department } & \multicolumn{2}{c}{ Ethnology Department } \\
\cline { 2 - 5 } & $\begin{array}{c}\text { Publication Rate } \\
\text { (Papers/Year) }\end{array}$ & $\begin{array}{c}\text { Articles Published } \\
\text { in English }(\%)\end{array}$ & $\begin{array}{c}\text { Publication Rate } \\
\text { (Papers/Year) }\end{array}$ & $\begin{array}{c}\text { Articles Published } \\
\text { in English (\%) }\end{array}$ \\
\hline 1993 & 1.48 & 0 & 0.78 & 0 \\
2003 & 1.67 & 0 & 0.78 & 0 \\
2013 & 4.17 & 24 & 1.3 & 0 \\
\hline
\end{tabular}

Since 2000, English has become a barrier for some faculty but less so for junior faculty, more of whom still work under probation contracts, and who more commonly gained their Ph.D. abroad in an English language system. According to one informant, "junior faculty in Education ... now tend to publish more papers in English and have no Chinese books... partly due to promotion requirements in which SSCI or TSSCI ${ }^{1}$ carry more weight with the academic senate whose members also support this mentality.... The younger educational experts become less-known in the education profession and are alienated from local educational practices." Another education professor reflects that: "The trade-off is that now you have created a generation who are good at and more used to publishing English papers and have more exposure and network in the international community. But at the same time, they are less likely and show no interest in engaging in local educational discourse and practices accessible to the taxpayers."

\subsection{Hong Kong: Post-colonial publication?}

Our focal institution in Hong Kong is still supported by British finance practices and comes under the

${ }_{1}^{1}$ TSSCI was first introduced by National Science Council (Taiwan) in 1995 endeavours to standardize local academic journals via few fixed criteria including Chinese language and external peer-review.

78 Consortia Academia Publishing (A partner of Network of Professional Researchers and Educators) 
Special Administrative Region's University Grants Committee (UGC). After Hong Kong's 1997 return to China, higher education funding was more closely linked to the research performance of individual higher education institutions. Rather like Australia, research products were classified into five categories: world leading (4 star), internationally excellent (3 star), international standing (2 star), regional standing (1 star), and unclassified, although Hong Kong employed the four definitions of scholarship from the Carnegie Foundation, i.e., discovery, integration, application and teaching (Boyer, 1990; Glassick, Huber, \& Maeroff, 1997). The results of annual competitions for funding from the Research Grants Council (RGC) are projected to increase, with scores eventually accounting for half of the research allocation, while the Research Assessment Exercise (RAE) results will inform the other half of the research allocation.

Most of our Hong Kong interviewees endorsed the view that research is one of the core missions of universities, especially of research-intensive universities. Almost all interviewees agreed that they were highly motivated to serve this mission in their respective institutions. Institutionally, our focal institution in Hong Kong considers other dimensions of scholarship than only publication. However, in practice research is usually viewed as the most important criteria. Productivity at the focal institution was likely affected by the RAE: from 1993 to 2013, journal articles per faculty member increased sharply from 0.47 to 1.50 (Table 3 and Figure 2).

The pressure felt particularly by junior professors can be understood from the changing impact of research assessment exercises. Faculty publication at our focal institution in Hong Kong clearly was strongly affected by the RAE from 1993 to 2013. In 1993, the ratio of Chinese language to English publication was just 1:1.25 (still remarkable when considering that this was a Chinese medium institution). In the post-colonial period, this had risen 1:4.25 (i.e. there were 4.25 English publications for ever one in Chinese). Thus, in the post-Colonial period there was a far greater production of English-language publication than during the Colonial period (Table 4 and Figure 3). Research assessment exercises do not explicitly use the indicators of SCI, EI and SSCI journals for faculty advancement, substantiation, or for awards. But our focal higher education institution does have such expectations for English publications, even though this expectation is non-transparent in the external and internal review processes. English language publication is crucial for faculty substantiation ("tenure") so no academic dares to ignore these hidden rules. More senior faculty informants tended to agree on the global standards set by various assessment schemes; junior faculty felt the pressure. One junior professor felt the institutional pressure of research assessment exercises in this way: "There is a weird, performance-counts-all mentality like a ghost haunting Hong Kong universities, that is, if I am unable to meet the high expectation in terms of research outputs my university can easily find somebody else who can replace me, and this is the case in other local institutions too. I don't feel I myself am that treasured by my university."

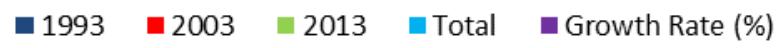

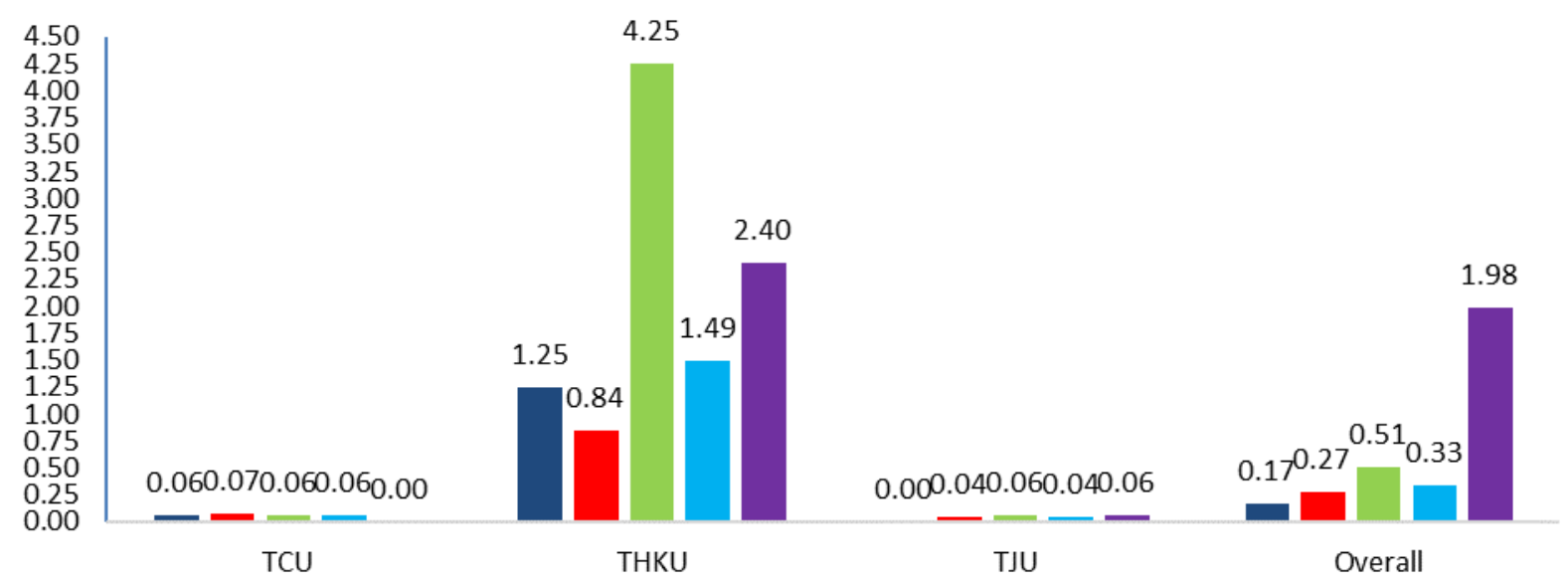

Note. Data excluding those that were published in bilingual journals or other local languages

Figure 3. Ratio Trends of Journal Articles in English and Native Languages (1993-2013) 


\subsection{Japan: Autonomy under pressure from “Super Global University” Project}

In contrast with the Hong Kong and the Taiwanese experience, in Japan we found a different response to global publication pressures. Fifteen years ago, Alatas (2003) referred to the distinctive independence of Japan's social science scholarship as "opting out" of the game of measuring academic success by publications in Western periodicals and in English. Alatas's argument is supported by an earlier work of Lie (1996, Chapter 8). Lie pointed out a profusion of publications produced by a sizable local scholarly community (e.g. Japan has the second largest national sociological association in the world) in academic journals, department publications, publicly circulated periodicals and interdisciplinary journals, books and edited volumes, as well as a large number of translated works of Western classics and monographs, all in Japanese. However, these accounts were developed before the proliferation of various world university rankings. Such institutional rankings and their popularity risk destabilizing the system of vernacular scholarship in Japan. Nevertheless, by and large, we found that humanities and social science scholarship in Japan has -so far, at least - kept the autonomy observed by Lie twenty years ago.

But pressure is intensifying. There are signs of a policy-driven shift away from the "opt-out" past. We found subtle yet emerging changes in publishing trends in Japan and diverging aspirations among the older and younger generation of scholars. There is now a government-sponsored "Super Global University" (officially termed "Top Global University") project and a policy directive to divide all national universities into global, local, and specialized categories. These policies inevitably change the ways that operational and research funds are distributed and university audits are conducted, thus profoundly affecting the future course of vernacular humanities and social science scholarship in Japan. Although enhancement of global research engagement may be desirable over the long term (Altbach \& Mathews, 2015), it runs the risk of "compartmentalization" (Hanafi, 2011) by stratifying the national university system through uneven restructuring of local academia. Furthermore, the creation of "global universities" adheres to a narrow definition of science and scholarship, "namely one that can be captured by Anglophone neoliberal audit cultures" (Jöns \& Hoyler, 2013, p. 57). This definition may improve the ranking positions of Japanese universities in the short term, but it risks de-contextualization (Kang, 2009), as well as the demise of long-sustained local scholarship, and the loss of autonomy in vernacular knowledge production.

At our focal institution, we found that education research articles (as well as those in Anthropology) had changed little in terms of authorship or language. An overwhelming majority were single-authored articles written in the Japanese language and published in Japanese journals and periodicals (Table 6). The education scholars in this study primarily published for the national scholarly community and intellectual readership. However, international contents such as comparative analyses with other countries or internationalization of local schools have become more common in recent years. Our tabulations showed that books continue to be favored over articles. Articles in academic journals are often considered milestones to publishing books. Books are more accessible for the general public than are professional journals. The education scholars we analyzed also continued to publish articles in intellectual journals, popular magazines, government bulletins, and newspapers (Table 7).

Nevertheless, both senior and junior faculty members we interviewed noted the growing importance of publishing internationally and they predicted an increase in English-language publications. Younger scholars expressed greater willingness to publish articles in English in international journals. For them, international research outputs and expertise (for example, presenting papers at international conferences and participating in international research collaboration) are becoming a requirement for obtaining faculty positions in research universities. Despite this, English and Japanese articles are evaluated equally under current academic norms and practices. Young researchers interviewed are therefore often torn between writing one English article and producing higher quality articles in Japanese. Senior scholars publish in English in international journals as an outcome of international collaboration or by invitation. At least among those interviewed for this study, no reference was made to strategically choosing certain prestigious journals such as those listed in SSCI for

80 Consortia Academia Publishing (A partner of Network of Professional Researchers and Educators) 
World class university publication pressure across different systems

recognition. In Japan there is a continued commitment to locally relevant research at the expense of global recognition. But the government's declared goal to make some of the nation's top universities "super global" places this vernacular scholarship at greater risk.

Table 6

Japan Case: Profile of documentation research - Osaka University

\begin{tabular}{ccccccc}
\hline \multirow{2}{*}{$\begin{array}{c}\text { Date } \\
\text { Point }\end{array}$} & \multicolumn{2}{c}{ Anthropology Department } & \multicolumn{2}{c}{ Education Policy Department } \\
\cline { 2 - 6 } & $\begin{array}{c}\text { No. of } \\
\text { Researchers }\end{array}$ & $\begin{array}{c}\text { No. of } \\
\text { Articles }\end{array}$ & $\begin{array}{c}\text { Articles } \\
\text { Published in } \\
\text { English }(\%)\end{array}$ & $\begin{array}{c}\text { No. of } \\
\text { Researchers }\end{array}$ & $\begin{array}{c}\text { No. of } \\
\text { Articles }\end{array}$ & $\begin{array}{c}\text { Articles } \\
\text { Published in } \\
\text { English }(\%)\end{array}$ \\
\hline 1993 & 4 & 202 & 1.5 & 6 & 434 & 0.5 \\
2003 & 4 & 79 & 7 & 5 & 250 & 0.8 \\
2013 & 4 & 84 & 7 & 4 & 250 & 2.3 \\
\hline
\end{tabular}

\section{Table 7}

Japan Case: Publishing by selected senior scholars in both fields

\begin{tabular}{lcccc}
\hline & Anthropology Department & \multicolumn{2}{c}{ Education Policy Department } \\
\hline Scholars & $\mathrm{A}$ & $\mathrm{B}$ & $\mathrm{C}$ & $\mathrm{D}$ \\
Number of Books \& & 27 & 17 & 67 & 25 \\
Edited Volumes & & & 5 & - \\
Translated Books & 4 & - & 223 & 82 \\
Articles \& Others & 152 & 27 & & \\
\hline
\end{tabular}

\subsection{Pressure? What Pressure? US educational researchers in contrast}

Even compared to Japanese autonomy, education researchers in the United States feel little national-level or global pressure, and this was evident within our focal US institution. We first created a roster of names of all professors with full-time appointments who worked in a social science department and an education policy department in 1993, 2003, and 2013. We then used "Google Scholar" to create an inventory of their published research during each year. We only coded each journal publication in different factors, including: the year of publication and so forth accordingly. We then compared over time tendencies in research articles by faculty. Additionally, when we inspected the format of Curricula Vita available on-line, we were able to note whether professors have tended to include journal ranking and Impact Factor statistics with their publications as possible indicators of quality. There was a near total absence of any such statistics in the CVs. Our data base included a cumulative total of 420 research articles published in journals over the careers of faculty members of a social science department who were still in the department in 2013. In addition, our data included information on a further 94 articles by members of this same department in 1993, but who were not working in the department in 2013. Our data base included a department of education policy with cumulative total of 560 research articles published in journals by the faculty members who worked in this department in 2013. In addition, we have information about a further 115 articles published by authors who were members of this department in 1993, but who were not affiliated with the department in 2013 (Table 8).

Among the cumulative total of 560 research articles published in the education department, all but seven appeared in English (five were in Spanish, and two in French). This might seem unsurprising, since the focus of education research is usually national. However, the focus of the article (at least as indicted by the article title) was not always the United States or any English-speaking country. Fifty-seven titles of these articles indicated that they were studies of some non-English-language country, in addition to the seven non-English articles previously mentioned. As we compared the articles over time, we found that the focus of research had become slightly more international, but the language of publication has not, and the site of publication has remained almost exclusively in US journals. 
In the social science department at the same university, only 57 of the 420 publications by faculty in 2013 were focused on the contemporary United States (although there were archeological research articles on the colonial and pre-colonial period). Most publications, not surprisingly, were focused on non-English-language societies, but only nine publications were not in English (all in Spanish archeological journals). Among faculty members of the same department 20 years earlier, but who were not in the department in 2013, out of the 94 articles published cumulatively by 1993 only two were focused explicitly on the United States. None of the 94 articles were in languages other than English.

\section{Table 8}

United States Case: Research inside two departments of a U.S. research university

\begin{tabular}{lcccccc}
\hline Department & Year & $\begin{array}{c}\text { Focus of } \\
\text { Research } \\
\text { National }\end{array}$ & $\begin{array}{c}\text { Focus of } \\
\text { Research } \\
\text { International }\end{array}$ & $\begin{array}{c}\text { Number of } \\
\text { English } \\
\text { Language } \\
\text { Publications }\end{array}$ & $\begin{array}{c}\text { Number of } \\
\text { Non-English } \\
\text { Language } \\
\text { Publications }\end{array}$ & $\begin{array}{c}\text { Number of } \\
\text { Articles } \\
\text { Published }\end{array}$ \\
\hline $\begin{array}{l}\text { Education } \\
\begin{array}{l}\text { Policy } \\
\text { Education }\end{array}\end{array}$ & 1993 & 114 & 1 & 114 & 1 & $115 / 560$ \\
$\begin{array}{l}\text { Policy } \\
\text { Social Science }\end{array}$ & 1993 & 503 & 57 & 553 & 7 & 560 \\
Social Science & 2013 & 57 & 92 & 94 & 0 & $94 / 420$ \\
\hline
\end{tabular}

Interviews with American researchers at our focal institution showed they felt no extrinsic pressure to publish in particular journals. Although there were incentives to publish in "top" journals, the definitions for "top" were left to researchers, who were most influenced by their own experiences reading these journals as part of a professional association or from the time they were students. Those interviewed had only a vague awareness of the ranking pressures seen elsewhere in the world. None interviewed could identify the precise origin of the pressure of where they should publish their research, because there was never an authorized list from the university, local government, or US government to indicate while publication outlets were most strategic. As one informant told us, "from the department there were sort of clear expectations - maybe stated explicitly maybe not - that you needed to publish a couple of articles a year in good places, decent places." Another researcher reflected on his publication strategy, saying that "I never felt much pressure because I already had two books out.... the only pressure I felt was that I better publish something in a higher education journal.... People basically said do whatever you want as long as you publish."

Funded research, for example from the Institute of Educational Sciences, creates pressures to publish. Unlike in other countries, there is no explicit formula of how or where to publish, and there is not even a strict requirement for publishing previously-funded research. However, informants felt morally obligated to see their funded work into print. Even researchers who regularly studied and published on non-English countries felt no pressure to publish in other languages. As one informant stated, "My Spanish wasn't good enough so I don't think I ever thought of it. I mean I guess I could have had somebody else translate it, but I didn't feel .... like it was an audience I was trying to reach. There was no need to write in another language since my audience was English speaking." The same perspective was shared by another interviewee.

"None of my stuff has appeared in any foreign language journal that I know of and I have not attempted to publish any of my research in, for example, a Spanish language journal. It would take more work, more resources than it would be worth to publish in a non-English language journal... It would take both time and money.... Who needs it though?"

In contrast with the previous 30 decades, today US academics are becoming somewhat aware of the use of journal metrics. However, in none of the four publication trajectories did our informants state that they themselves had used these metrics as the reason for publication or for pursuing a line of research. It is striking that sensitivities that have been felt for much longer outside the US are only now becoming apparent in this US 
university. We asked one very senior and widely-published scholar, "At what point did first hear the term "impact factor?" The reply would have been unexpected in the other countries of our investigation, but expected in the United States: "I don't think it was early in my career; I think it was really more like five or ten years ago. I don't know when it started." Only one interviewee saw advantages to using citation indexes in order to determine the usual impact of articles published in particular journals.

"There is the possibility that if you send a paper to a higher impact journal, it will be more visible and the paper itself will have more influence. This is the only reason why you would ever use [the Impact Factor]. You want to be more visible in terms of your professional activities. If that wasn't important, I would just write up a paper for the fun of writing it up and put it in my file cabinet, right? But nobody wants to do that because we all want to do research that is relevant and potentially has an impact on something."

Because (unlike the other six cases of our project) the US has no central Federal funding mechanism in the US, there are no national standards or metrics by which universities are judged and funded. There has been a popularized, well-known attempt by a for-profit firm (US News) to rank universities and programs of study using combinations of subjective and objective criteria that are weighted in particular combinations (but where faculty research is only a small component). ${ }^{2}$ The US illustrates that, in the absence of external national pressures, scholars can produce and publish research based on their own criteria about its worth. Pressure to publish in certain journals has been felt relatively less in American universities than in countries that rely on government-imposed journal lists and where English is not a medium of instruction.

\section{Conclusions}

Quality assurance has been an increasing concern in higher education world-wide, including in the US (Harman \& McDowell, 2011; Teichler, 2011). Quality monitoring and evaluation are viewed as serving "organizational effectiveness" (Shin, 2011) and "research quality and impact" (Harman, 2011) also as a "transparency tool" (van Vught \& Westerheijden, 2012), an "audit culture" (Power, 2004) and an "accountability movement" (Toutkoushian \& Webber, 2011). One purpose of our study is to show how the global ranking regime affected higher education in different settings (Hazelkorn, 2015), in the move from how to rank, to why to rank (Oguz, 2004), and indeed to so what to rank.

David Bridges, a past president of the British Educational Research Association, (2011, p. 33) summarized the key problem that comes from using proxy measures of university quality as targets is the resulting distortion of behavior that invalidates the original evidence of an extrinsic indicator having a probabilistic relationship with intrinsic features of quality. Or, if we apply this comment to countries where university funding is tied to research productivity, it is clear that it becomes harder to identify objective indicators for quality when the indicators are being used as targets.

It is ironic that one of the leaders in the new academic ranking industry, the director of Shanghai Jiao Tong's "Center for World-Class Universities" has stated that the pursuit of the aims of countries to achieve "higher ranking or more top-ranked universities should not be encouraged until the rankings are based on what a university or a country really wants." But what would be the mechanism to bring a ranking system into alignment with the wants of any particular university or country?

Based on the results of this study it is evident that Clark's "triangle of coordination" model is an applicable model to the influences of globalization, neoliberalism, and new managerialism in higher education. As displayed in Figure 1, all universities in this study are public institutions which depend on public funding and need to comply with government governance and policy to a great extent. As many governments are pressured to

2 see alternative evaluations by The Washington Monthly and by Colleges That Change Lives. 
boost up local HEIs to world class status, these targeted universities adopt the audit system from the neo-liberal and new managerial ideology to monitor university performances and outcomes through quantification of faculty research and publications. Our research shows that most higher education systems did not start this inclusion of an external auditing system until the early 2000s when the impact of the world-class university ranking began to surge. As a result, academic culture including faculty research and publication has been geared toward more extrinsic and instrumental outcomes such as striving for international journal publication with more mainstream research topics (Chou \& Chan, 2017).

This study is crucial in understanding how global influences of higher education have differing effects on diverse higher education systems. What makes this study unique is its utilization of a comparative framework to highlight higher education publication patterns among the 8 higher education systems. The results indicate that certain higher education systems bear unequal costs for the pursuit of "world class" status. In some cases, higher education faculty report a significant decline in knowledge production in native languages of their respective, non-English predominant, societies.

We conclude that educational researchers must take ownership - must own - their own quality assessment within national research cultures and contexts. In each country, we advocate that academics problematize how to appreciate and recognized the value scholarly inquiry and the basis on which it ultimately is thought to have an impact. University professors do have options in the face of global rankings. After reflection, the knowledge-workers in some countries may decide that they prefer to retake control over the creation of multiple, complementary criteria of quality universities.

\section{References}

Alatas, S. F. (2003). Academic dependency and the global division of labour in the social sciences. Current Sociology, 51(6), 599-613. https://doi.org/10.1177/00113921030516003

Altbach, P. G., \& Mathews, E. (2015). India's need for higher education internationalization. International Higher Education, 82, 23-25. https://doi.org/10.6017/ihe.2015.82.8874

Boyer, E. L. (1990). Scholarship Reconsidered: Priorities of the Professoriate. New York: The Carnegie Foundation for the Advancement of Teaching.

Bridges, D. (2011). Research quality assessment: Intended and unintended consequences. Power and Education, 3(1), 31-38. https://doi.org/10.2304/power.2011.3.1.31

Chou, C. P., \& Chan, C. F. (2017). Governance and academic culture in higher education: Under the influence of the SSCI syndrome. Journal of International and Comparative Education, 6(2), 63-75. https://doi.org/10.14425/jice.2017.6.2.63

Chou, C. P., \& Ching, G. (2012). Taiwan education at the crossroad: When globalization meets localization. New York: Palgrave Macmillan. https://doi.org/10.1057/9780230120143

Clark, B. R. (1986). The higher education system: Academic organization in cross-national perspective. Berkeley; University of California Press.

Deem, R., \& Brehony, K. J. (2005). Management as ideology: The case of 'new managerialism' in higher education. Oxford Review of Education, 31(2), 217-235. https://doi.org/10.1080/03054980500117827

Glassick, C. E., Hubert, M. T., \& Maeroff, G. I. (1997). Scholarship assessed: evaluation of the professoriate. Special report. San Francisco: Jossey Bass.

Hanafi, S. (2011). University systems in the Arab East: Publish globally and perish locally vs publish locally and perish globally. Current Sociology, 59(3), 291-309. https://doi.org/10.1177/0011392111400782

Harman, K., \& McDowell, L. (2011). Assessment talk in design: The multiple purposes of assessment in HE. Teaching in Higher Education, 16(1), 41-52. https://doi.org/10.1080/13562517.2010.507309

Hazelkorn, E. (2011). Measuring world-class excellence and the global obsession with rankings. In R. King, S. Marginson, \& R. Naidoo (Eds.). Handbook on globalization and higher education. Cheltenham, UK: Edward Elgar Publishing.

Hazelkorn, E. (2013). Higher education's future: A new global order? In R. Pritchard \& J. E. Karlsen (Eds.), 
Resilient universities. Oxford: Peter Lang Publishers.

Hazelkorn, E. (2015). Rankings and the reshaping of higher education: The battle for world-class excellence. London: Palgrave Macmillan UK. https://doi.org/10.1057/9781137446671

Jansen, J. (2013). Not even colonial born: England, the English and the problem of education in South Africa. Lesig vir die English Academy of South Africa, 18.

Jöns, H., \& Hoyler, M. (2013). Global geographies of higher education: The perspective of world university rankings. Geoforum, 46, 45-59. https://doi.org/10.1016/j.geoforum.2012.12.014

Lie, J. (1996). Sociology of contemporary japan, Trend report. Current Sociology, 44(1), 1-101. https://doi.org/10.1177/001139296044001003

Lo, W. Y. W. (2014). University rankings: Implications for higher education in Taiwan. Singapore: Springer. https://doi.org/10.1007/978-981-4560-35-1

Miller, P. (2001). Governing by numbers: Why calculative practices matter. Social research, 68(2), 379-396.

Mok, K. H. (2014). Promoting the global university in Taiwan: University governance reforms and academic reflections. In C. P. Chou (Ed.), The SSCI syndrome in higher education. Leiden: Brill / Sense. https://doi.org/10.1007/978-94-6209-407-9_1

Oguz, A. (2004). Ranking competition: How much to endeavor to move up? (UMI Number: 1421982) [Master of Arts thesis, Emory University]. ProQuest Dissertations Publishing.

Power, M. (2004). The risk management of everything: Rethinking the politics of uncertainty. London: Demos.

Quacquarelli Symonds. (2015). QS world university rankings 2015/16. Retrieved from QS Top Universities https://www.topuniversities.com/university-rankings/world-university-rankings/2015\#sorting=rank+reg ion $=+$ country $=+$ faculty $=+$ stars $=$ false + search $=$ national $\% 20$ taiwan $\% 20$ university

Shin, J. C. (2011). Organizational effectiveness and university rankings. In J. Shin, R. Toutkoushian, and U. Teichler (Eds.), University rankings. The changing academy - The changing academic profession in international comparative perspective, vol 3. Springer: Dordrecht. https://doi.org/10.1007/978-94-007-1116-7

Shore, C. (2008). Audit culture and Illiberal governance: Universities and the politics of accountability, Anthropological Theory, 8(3), 278-298. https://doi.org/10.1177/1463499608093815

Shore, C., \& Wright, S. (1999). Audit culture and anthropology: Neo-liberalism in British higher education. The Journal of the Royal Anthropological Institute, 5(4), 557-575.https://doi.org/10.2307/2661148

Shore, C., \& Wright, S. (2015). Audit culture revisited. Current Anthropology, 56(3), 421-444. https://doi.org/10.1086/681534

Suh, G. S., \& Park, S. J. (2014). The Korean government's policies and strategies to foster world-class universities. In Y. Cheng, Q. Wang, and N. C. Liu (Eds.), How world-class universities affect global higher education: influences and responses. Singapore: Springer. https://doi.org/10.1007/978-94-6209-821-3_6

Teichler, U. (2011). Social contexts and systemic consequence of university rankings: A meta-analysis of the ranking literature. In J. Shin, R. Toutkoushian, and U. Teichler (Eds.), University rankings. The changing academy - The changing academic profession in international comparative perspective, vol 3. Springer: Dordrecht. https://doi.org/10.1007/978-94-007-1116-7_4

Toutkoushian, R. K., \& Webber, K. (2011). Measuring the Research Performance of Postsecondary Institutions. In Shin J., Toutkoushian R., Teichler U. (Eds.). University Rankings. The Changing Academy - The Changing Academic Profession in International Comparative Perspective, vol 3. Springer: Dordrecht. https://doi.org/10.1007/978-94-007-1116-7_7

van Vught F. A., \& Westerheijden, D. F. (2012). Transparency, quality and accountability. In F. van Vught F. and F. Ziegele (Eds.), Multidimensional ranking: The design and development of $U$-multirank. Higher education dynamics, vol 37. Springer: Dordrecht. https://doi.org/10.1007/978-94-007-3005-2

Welch, A. (1998). Education of the cult of efficiency: Comparative reflections on the reality and the rhetoric, Comparative Education, 34(2), 157-175. https://doi.org/10.1080/03050069828252

Welch, A. (2005). Accountability or accountancy? Governance and university evaluation systems in an era of performativity, Comparative and International Education Review, 5, 116-144. 
Post, D., Chou, C. P., Ishikawa, M., Li, J., Soudien, C., \& Welch, A.

World of Science. (2014). Science Citation Index. New York: Thomson Reuters.

86 Consortia Academia Publishing (A partner of Network of Professional Researchers and Educators) 